\title{
Vitamin Supplements and Purported Learning Enhancement in Mentally Retarded Children
}

\author{
Frank J. Menolascino,* John Y. Donaldson, Thomas F. GallagheR, \\ Charles J. Golden, James E. Wilson, Jeffrey A. Huth, \\ Carl W. Ludvigsen, and Daniel W. Gillette \\ University of Nebraska Medical Center, Omaha, Nebraska 68105, USA
}

(Received January 30, 1989)

\begin{abstract}
Summary Dr. Ruth Harrell and her colleagues conducted a study in 1981 in which the administration of high dosages of vitamins were determined to dramatically improve the intellectual functioning of mentally retarded children. This paper documents the efforts of its authors to replicate the Harrell et al. research and, although no significant differences were found between active treatment groups and control groups at study's end, a thorough comparison is made between the two research efforts.

Key Words megavitamin therapy, mental retardation, human, children, nutritional supplements, learning enhancement, thyroid supplementation, Down's syndrome
\end{abstract}

In January of 1981, Dr. Ruth Harrell and her colleagues published the results of a study involving the treatment of 16 home-reared mentally retarded children with the megavitamin supplement GTC (Bronson Co., La Canada, Calif.) and dietary restrictions. In addition, it was determined via the Barnes Test (1) that all but one of the children required desiccated thyroid supplementation, which was simultaneously administered in dosages ranging from 0.5 to 2.5 grains per day. The eight-month study consisted of double-blind experimental and control groups for four months, after which all subjects were placed on active agents. The IQs of the children studied ranged from 17 to 70 , the ages from 5 to 15(2).

Following the first four months, five of the six supplemented childrens' IQs were reported to have increased by an average of 5.0 to 9.6 points, depending upon the investigator, while the IQs of the children receiving placebo and thyroid showed no significant change. After an additional four months, the children who had previously received placebo were placed on active preparations and demonstrated an average IQ increase of 10.2 points.

The Harrell group concluded, therefore, that mental retardation may have a genetotrophic basis and that an increase in the supply of vitamins, minerals, and thyroid may have helped to ameliorate the condition of these children by making

* To whom all correspondence should be addressed. 
their enzymatic transformations work more efficiently. Since the control group, which had received only placebo and thyroid, had shown only negligible changes, it was also concluded that it was not the thyroid supplement alone that had caused intellectual improvements to occur.

Since its publication, the Harrell et al. exploratory study has evoked continuing controversy and, in answer to the challenge which concluded their paper, other researchers have attempted to prove or disprove the study's results (3-6). Yet a number of methodological flaws have been detected in the study design itself; lack of random subject assignment, no tests for compliance, statistical errors, etc. Many have tried to correct these design flaws, yet important variables have often been altered in the attempt.

Nevertheless, some research in the area of megavitamin therapy has had positive results $(7,8)$ but it cannot be cited as evidence in favor of the Harrell et al. findings because experimental designs were dissimilar. To date, no study has either replicated the original Harrell et al. experiment without significantly altering important variables or corrected its reported methodological errors. Such studies do, however, stimulate interest for further research.

\section{METHODS}

Subjects. Twenty-four mentally retarded children, aged 5 to 15 years, were enrolled in a double-blind study for a period of eight months. These children, 12 of whom were male and 12 female, all lived in private homes with natural or adoptive parents except one, who lived in a group home. All attended special education programs and were, therefore, receiving developmental stimulation adequate to realize any increase in intellectual capacities which may have occurred secondary to the treatment regimen. All previously assessed intelligence quotients ranged from 35 to 69. Specific group assignments, known etiologies, and chronological ages are summarized in Table1. Procedures developed by the University of Nebraska Medical Center and the Association for Retarded Citizens of the United States for explaining the purpose and nature of the proposed study, as well as assuring Informed Consent of the subjects and/or their parents, were implemented upon initial contact.

The children were randomly assigned to the various study conditions as they enrolled. Variable 1, vitamin-mineral supplementation, consisted of two groups; a placebo condition, and an active GTC\#3 condition. Variable 2, thyroid supplementation, also consisted of two conditions; administration of either active desiccated thyroid (Armour Company) or identical thyroid placebo. The Harrell et al. study had assigned quantities of thyroid on the basis of physical size and underarm body temperature, resulting in the administration of amounts ranging from 0.0 to 2.5 grains per day. Yet their study has been criticized on the grounds that the Barnes method is not a reliable test of thyroid functioning (9). So as to assure replication, the children in our study had both oral and axillary baseline temperatures taken, as well as baseline serum T3, T4, and T7 laboratory 
Table 1. Sample population of a megavitamin replication studya.

\begin{tabular}{|c|c|c|c|c|c|c|c|c|c|}
\hline \multicolumn{5}{|c|}{ Group I } & \multicolumn{5}{|c|}{ Group IV } \\
\hline \multirow[t]{2}{*}{ Subject } & \multirow[t]{2}{*}{ Etiology } & \multicolumn{2}{|c|}{ Initial age } & \multirow[t]{2}{*}{ Sex } & \multirow[t]{2}{*}{ Subject } & \multirow[t]{2}{*}{ Etiology } & \multicolumn{2}{|c|}{ Initial age } & \multirow[t]{2}{*}{ Sex } \\
\hline & & Year 1 & onth & & & & Year & onth & \\
\hline SH & Down's & 8 & 1 & $\mathbf{M}$ & DK & Unknown & 6 & 8 & $\mathbf{M}$ \\
\hline $\mathrm{NN}$ & Down's & 10 & 6 & $\mathbf{M}$ & KS & Unknown & 10 & 0 & $\mathbf{M}$ \\
\hline AR & Down's & 5 & 1 & $\mathrm{~F}$ & SS & Down's & 7 & 10 & $\mathbf{F}$ \\
\hline JW & Down's & 12 & 2 & F & LH & Unknwon & 13 & 11 & $\mathrm{~F}$ \\
\hline DB & Unknown & 14 & 3 & $\mathrm{~F}$ & & & & & \\
\hline NM & Unknown & 12 & 3 & $\mathrm{~F}$ & & & & & \\
\hline \multicolumn{5}{|c|}{ Group II } & \multicolumn{5}{|c|}{ Group V } \\
\hline \multirow[t]{2}{*}{ Subject } & Etiology & \multicolumn{2}{|c|}{ Initial age } & Sex & Subject & Eticlogy & \multicolumn{2}{|c|}{ Initial age } & Sex \\
\hline & & \multicolumn{3}{|c|}{ Year Month } & & & \multicolumn{2}{|c|}{ Year Month } & \\
\hline CG & Unknown & 14 & 10 & $\mathbf{M}$ & MC & Down's & 7 & 7 & $\mathbf{M}$ \\
\hline $\mathrm{CM}$ & Unknown & 12 & 10 & $\mathbf{M}$ & ER & Down's & 10 & 3 & $\mathbf{M}$ \\
\hline FO & Down's & 8 & 9 & $\mathbf{M}$ & $\mathbf{J M}$ & Down's & 10 & 6 & $F$ \\
\hline $\mathbf{R C}$ & Down's & 14 & 2 & $\mathbf{F}$ & DT & Unknown & 14 & 7 & $\mathrm{~F}$ \\
\hline \multirow[t]{2}{*}{ SE } & $\mathrm{Chr} / 2 \mathrm{del}$ & 8 & 5 & $\mathrm{~F}$ & & & & & \\
\hline & \multicolumn{3}{|c|}{ Group III } & & & & & & \\
\hline \multirow[t]{2}{*}{ Subject } & Etiology & \multicolumn{2}{|c|}{ Initial age } & Sex & & & & & \\
\hline & & \multicolumn{2}{|c|}{ Year Month } & & & & & & \\
\hline KD & Down's & 6 & 6 & $\mathrm{~F}$ & & & & & \\
\hline ChG & Unknown & 14 & 10 & $\mathbf{M}$ & & & & & \\
\hline PG & Unknown & 13 & 3 & $\mathbf{M}$ & & & & & \\
\hline RM & Down's & 8 & 10 & $\mathbf{M}$ & & & & & \\
\hline NB & Noonan's & 11 & 7 & $F$ & & & & & \\
\hline
\end{tabular}

$N=24$. Down's = Down's syndrome; Noonan's = Noonan's syndrome $; \mathrm{Chr} / 2 \mathrm{del}=$ Deletion from the short arm of chromosome \#2. ${ }^{a}$ The subjects were randomly assigned to the five groups. Of the initial 30 subjects enrolled, six dropped out due to: family geographical moves (three); side effects (one); non-compliance to the study protocol (two).

determinations. Since none of our subjects had positive Barnes Tests, our endocrinology co-investigator decided, in view of the heights, weights, and ages of our subjects, that a fixed dosage of 1.0 grain of desiccated thyroid per day should be administered to each. Lastly, Harrell et al. had administered desiccated thyroid to both experimental and control groups for a total of eight months. Our study 
Table 2. GTC\#3 composition compared to RDA, MSI and VSI.

\begin{tabular}{|c|c|c|c|}
\hline & $\begin{array}{c}12 \\
\text { Tablets } \\
\text { provide } \\
\text { (GTC\#3) }\end{array}$ & $\begin{array}{l}\text { Approximate \% } \\
\text { RDA (1982) } \\
\text { Multiple of } \\
\text { RDA (1982) } \\
\text { provided. One } \\
\text { equals } 100 \% \text { of } \\
\text { the RDA }\end{array}$ & $\begin{array}{l}\text { Mineral Safety Index (MSI) } \\
\text { or Vitamin Safety Index } \\
\text { (VSI) as calculated from } \\
\text { the Minimum Toxic Dose } \\
\text { (MTD) and expressed as the } \\
\text { multiple of the RDA which } \\
\text { reaches the MTD }\end{array}$ \\
\hline $\begin{array}{l}\text { Vitamin A } \\
\text { (Palmitate) }\end{array}$ & $5,000 \mathrm{IU}$ & 3.0 & 5 to 10 \\
\hline $\begin{array}{l}\text { Vitamin D } \\
\text { (Cholecalciferol) }\end{array}$ & $300 \mathrm{IU}$ & 0.75 & 125 \\
\hline $\begin{array}{l}\text { Thiamine } \\
\text { (Mononitrate) }\end{array}$ & $300 \mathrm{mg} *$ & 200 & 200 \\
\hline Riboflavin & $200 \mathrm{mg}$ & 117.6 & 588 \\
\hline Niacinamide & $750 \mathrm{mg}$ & 37.5 & 50 \\
\hline $\begin{array}{l}\text { Pantothenic acid } \\
\text { (Calcium pantothenate) }\end{array}$ & $450 \mathrm{mg}$ & 450.0 & 1,000 \\
\hline $\begin{array}{l}\text { Vitamin } \mathrm{B}_{6} \\
\quad \text { (Pyridoxine } \mathrm{HCl} \text { ) }\end{array}$ & $350 \mathrm{mg}$ & 175.0 & 900 \\
\hline $\begin{array}{l}\text { Vitamin } \mathbf{B}_{12} \\
\quad \text { (Cobalamin concentrate) }\end{array}$ & $1,000 \mu \mathrm{g}$ & 136.68 & - \\
\hline Folic Acid & $400 \mu \mathrm{g}$ & 1.0 & 1,000 \\
\hline $\begin{array}{l}\text { Vitamin C } \\
\text { (Ascorbic acid) }\end{array}$ & $1,500 \mathrm{mg}$ & 25.0 & 33 to 83 \\
\hline $\begin{array}{l}\text { Vitamin } \mathrm{E} \\
\text { (d-alpha tocopheryl } \\
\text { succinate) }\end{array}$ & $600 \mathrm{IU}$ & 25.0 & 40 \\
\hline $\begin{array}{l}\text { Magnesium } \\
\text { (Oxide) }\end{array}$ & $300 \mathrm{mg}$ & 0.75 & 15 \\
\hline $\begin{array}{l}\text { Calcium } \\
\text { (Carbonate) }\end{array}$ & $400 \mathrm{mg}$ & 0.40 & 10 \\
\hline Zinc & $30 \mathrm{mg}$ & 2.0 & 33 \\
\hline $\begin{array}{l}\text { Manganese } \\
\text { (Gluconate) }\end{array}$ & $3 \mathrm{mg}$ & $* *$ & $* *$ \\
\hline $\begin{array}{l}\text { Copper } \\
\text { (Gluconate) }\end{array}$ & $1.75 \mathrm{mg}$ & 0.88 & 33 \\
\hline $\begin{array}{l}\text { Iron } \\
\text { (Ferrous fumarate) }\end{array}$ & $7.5 \mathrm{mg}$ & 0.42 & 5.5 \\
\hline $\begin{array}{l}\text { Iodine } \\
\text { (Potassium iodide) }\end{array}$ & $0.144 \mathrm{mg}$ & 0.96 & 13 \\
\hline Biotin & $300 \mathrm{mg}$ & 1.0 & 167 \\
\hline
\end{tabular}

Plus dibasic calcium phosphate, magnesium stearate, glycerol monostearate, and silica capsule filler materials. Food glaze, titanium dioxide and calcium carbonate used in coating. ${ }^{*}$ The dosage for thiamine is equal to the MTD. ${ }^{* *}$ RDA not established and MSI not given. Placebo tablets consisted of: lactose, glycerol monostearate, magnesium stearate, annatto seed powder, guar gum and gum Arabic. Coated with food glaze, titanium dioxide and calcium carbonate. The GTC \#3 capsules and the placebo tablets were manufactured by the Bronson Pharmaceutical Company of La Canada, California 91011. 
utilized an four-month administration of thyroid only in Group III (see Table 3). At the end of four months, all subjects were placed on the active vitamin-mineral supplements and active desiccated thyroid, with the exception of Group V, which remained on placebo.

Our vitamin and mineral supplement GTC\#3, when compared to the supplement used in the Harrell et al. study, contained slight variations in biotin and calcium phosphate. Its contents and amounts are compared to Recommended Dietary Allowances and Vitamin or Mineral Safety Indices (10) and summarized in Table 2. Each of the parents were provided with personal instructions for feeding their child, particularly regarding the restriction of sugar, soft drinks, and "junk" foods. Following initial assessment by a clinical nutritionist, diets were regularly monitored so as to determine whether the parents had successfully modified their child's diet according to the instructions provided.

The five study cells to which the children were randomly assigned are summarized in Table 3. This design enabled an examination of the possible interactions between the vitamin/mineral supplement and the thyroid, and the effects of either supplement alone.

In summary, the study was very similar to that of the Harrell group, except that ours was larger in size, maintained its double-blind conditions, utilized a rationale for decreased amounts of desiccated thyroid, utilized a vitamin and mineral supplement which contained slight variations in biotin and calcium phosphate contents, and employed a control group in both phases of the study.

Specific study timetable. The children received an initial examination in which physical state was assessed, disorders determined, height, weight, and physical appearance recorded, and visual and auditory screenings conducted. An assessment

Table 3. Summary of study group treatment regimes in a megavitamin replication study.

\begin{tabular}{|c|c|c|}
\hline $\begin{array}{l}\text { Study } \\
\text { group }\end{array}$ & $\begin{array}{c}\text { Phase I } \\
\text { (First } 4 \text { months) }\end{array}$ & $\begin{array}{c}\text { Phase II } \\
\text { (Final } 4 \text { months) }\end{array}$ \\
\hline $\mathbf{I}$ & $\begin{array}{l}\text { active vitamin } \\
\text { active thyroid }\end{array}$ & $\begin{array}{l}\text { active vitamin } \\
\text { active thyroid }\end{array}$ \\
\hline II & $\begin{array}{l}\text { active vitamin } \\
\text { placebo thyroid }\end{array}$ & $\begin{array}{l}\text { active vitamin } \\
\text { active thyroid }\end{array}$ \\
\hline III & $\begin{array}{l}\text { placebo vitamin } \\
\text { active thyroid }\end{array}$ & $\begin{array}{l}\text { active vitamin } \\
\text { active thyroid }\end{array}$ \\
\hline IV & $\begin{array}{l}\text { placebo vitamin } \\
\text { placebo thyroid }\end{array}$ & $\begin{array}{l}\text { active vitamin } \\
\text { active thyroid }\end{array}$ \\
\hline $\mathbf{V}$ & $\begin{array}{l}\text { placebo vitamin } \\
\text { placebo thyroid }\end{array}$ & $\begin{array}{l}\text { placebo vitamin } \\
\text { placebo thyroid }\end{array}$ \\
\hline
\end{tabular}

Vol. 35, No. 3, 1989 
of diet was accomplished by a nutritionist, and guidelines and restrictions were studied with both the subjects and their parents. Evaluation records were reviewed so as to determine whether a potential subject's past intelligence scores were within or near the global intelligence range for this study. Project staff audited the results of all initial tests, which were, in turn, reviewed with the parents of potential study candidates.

Appointments were then finalized with the eligible study candidates for initial, four-month, and eight-month assessments of dependent variables. Finally, project staff met with the children and their parents to answer any remaining questions, sign all releases, and review exact procedures and timetables for the remainder of the study.

Drugs which had been administered at constant dosage levels for at least three months prior to baseline testing, such as anti-convulsants, were continued as usual, as were medications for specific illness, such as antibiotics. Parents were given the first month's supply of the study preparations, written dietary instructions, and weekly log sheets to record height, weight, and supplement administration. These logs were reviewed with the parents on a monthly basis. Parents were also regularly contacted regarding their child's compliance to the schedule of tablet ingestion and dietary habits. At the end of the first four months, and again at the end of eight, psychological testing was conducted, a urinalysis was obtained for gross determination of the presence of riboflavin, parents were interviewed regarding their child's behavioral status, height and weight were assessed, blood samples were taken to assess thyroid levels, and random studies were conducted to determine serum levels of vitamin A.

Dependent-independent variables. An evaluation of the major dependent variables was accomplished by an assessment of global intellectual level via the Wechsler Intelligence Scale for Children-Revised (11), social adaptive behavior via the Vineland Social Maturity Scale (12), and neuropsychological development via the Nebraska Neuropsychological Exam(13). Although both the Nebraska Neuropsychological Exam and the Wechsler are age-corrected, it is a questionable assumption that the mentally retarded develop in a manner which perfectly parallels normal development. Because there is no certain way to distinguish one child's normal developmental improvement from another's, which may be directly due to a concurrent treatment, a within-subjects analysis would be difficult to interpret. By utilizing a matched pairs or between-subjects design, as was accomplished in this study, the problem can be avoided. The remaining study variables were height, weight, visual and auditory status, physical examination parameters, and general appearance.

\section{RESULTS}

Four-month testing results were analyzed as four cells (i.e., Groups IV and V were identical during the first four months, and analyzed as members of the same 
cell) within a $2 \times 2$ square test of ANOVA, using The Statistical Package for the Social Sciences-Extended (14). This analysis generated results for both active vitamin and active thyroid $v s$. placebo, and for active vitamin and active thyroid together $v s$. either alone. The eight-month testing results consisted of two cells, active vitamin and active thyroid vs. the placebo of both, which were subjected to an ANOVA (essentially a T-test, since there were only two cells) to test for significant differences between the groups. Variables were tested at the end of four months for effects of active vitamin $v s$. placebo, active thyroid $v s$. placebo, and the interaction of active vitamin and thyroid. This statistical treatment generated $198 \mathrm{~F}$-scores, which one would randomly expect to show 9.9 statistically significant values at the 0.05 level. Variables in the final phase of the study were tested for active vitamin and active thyroid $v s$. the placebo. These tests generated a total of $66 \mathrm{~F}$-scores, which one would randomly expect to show 3.3 values significant at the 0.05 level. When so many F-scores are evaluated, the occurrence of random significances is important to consider since the input of random numbers will generate a significant result in an average of $5 \%$ of all cases.

Table 4 summarizes those parameters found to be significant at 0.05 (less than $5 \%$ chance of random occurrence). There were six parameters which demonstrated a significant difference in performance (improvement or decline) between the treatment groups. All of these occurred within the first four months, with no significant differences in performance detected on any of the measured parameters in the final four months. This is well within the number of random significances to be expected. Further, four of the six indicated superior improvement of the placebo

Table 4. Statistical results analysis in a megavitamin replication study.

First 4 months' significances:

\begin{tabular}{|c|c|c|}
\hline \multirow[t]{5}{*}{ Nebraska Neuropsychological Exam: } & : 4) & $\begin{array}{l}\text { Purposeful Movement }-0.037 \\
\text { Vitamin group significantly worse. }\end{array}$ \\
\hline & 6) & $\begin{array}{l}\text { Drawing }-0.023 \\
\text { Thyroid group significantly worse. }\end{array}$ \\
\hline & 15) & $\begin{array}{l}\text { Visual-Spatial }-0.003 \\
\text { Vitamin group significantly better. }\end{array}$ \\
\hline & 28) & $\begin{array}{l}\text { Reading Recognition }-0.041 \\
\text { Vitamin and Thyroid significantly worse } \\
\text { together. }\end{array}$ \\
\hline & 35) & $\begin{array}{l}\text { General Intelligence }-0.010 \\
\text { Vitamin group significantly better. }\end{array}$ \\
\hline Vineland Social Maturity Scale: & 2) & $\begin{array}{l}\text { Social Quotient }-0.029 \\
\text { Vitamin group significantly better. }\end{array}$ \\
\hline Second 4 months' significances & & None. \\
\hline
\end{tabular}


group over the treatment group, including the one indication of synergistic interaction between thyroid and vitamin supplementation.

The two areas where the treatment group significantly improved over the placebo group were visual-spatial skills on the Nebraska Neuropsychological Exam and the social quotient on the Vineland Adaptive Behavior scale. While it is conceivable that these two instances represent real improvement (and the four instances of poorer performance are random) this is not likely. This is made even less possible since these parameters were not found to be significant in the final four months. In fact, they were not close to significance since visual-spatial skills had an $\mathrm{F}$ of 0.276 and social quotient an $\mathrm{F}$ of 0.182 .

In light of these considerations, the significances found can only be viewed as random, and it may be said that neither the vitamin nor the thyroid supplementation significantly improved performance of the mentally retarded children studied, nor indeed was there significant synergistic interaction with simultaneous vitamin and thyroid supplementation.

\section{DISCUSSION}

Because replication was the aspect to be achieved, it is appropriate to go over each of the Harrell et al. study's findings and compare them with those of the current study. For example, the original results of the Harrell group were less impressive until the authors dropped one subject, who was known to have taken the vitamins only intermittently, from their statistical calculations. While noncompliance is a valid consideration, it is not valid after the double-blind code has been broken and the results calculated. In any case, our study found no significant changes in the Vineland Social Maturity Scale, the Nebraska Neuropsychological Exam, or the Wechsler raw, scaled, or full scale IQ scores.

The sex variable dimension of our study sample was directly comparable to the Harrell et al. study, as was the age spectrum. Dissimilar, however, were increases in height, which were noted in the Harrell et al. study sample as twice that of the control group. In contrast, our data on height changes did not indicate significant differences in any of the children. Harrell et al. noted irregular changes in weight, and our findings were similar. All urinalyses and complete blood counts were assessed as normal in both studies.

Unlike the Harrell et al. study, ours did not utilize the Barnes Test as the basis for the administration of flexible amounts of desiccated thyroid. Instead, we opted to utilize T3, T4, and T7 laboratory assessments, and a fixed dosage of 1.0 grain. Barnes (1) has stated that the basal temperature test which bears his name is a more valid clinical assessment of thyroid functioning than current laboratory trials. Although his thesis is debatable, our initial screening of axillary basal temperatures did not reveal any to be low. A case could certainly be made that higher or individualized dosages of thyroid should have been utilized in our study since no side effects attributable to thyroid status had been observed. We noted this non-toxicity dimension, however, only after the study had been complete. One could 
also argue that some of our subjects represented "marginal thyroid deficiencies" (15) and may have responded to higher amounts of desiccated thyroid. Although there are several reports $(16,17)$ that Down's syndrome children do have multiple thyroid/metabolic aberrations, and over half of our study sample was composed of Down's syndrome subjects, none had demonstrable thyroid deficiencies.

All of the subjects in the Harrell et al. study were able to tolerate the high dosages of vitamins and minerals with no significant side effects. In our research, however, two subjects developed diarrhea. While one responded promptly to symptomatic treatment and remained in the study, the other, who was later discovered to have been a control, did not follow treatment guidelines and refused to continue. This dimension of the relative non-toxicity of vitamin-mineral supplementation does not appear to be fully appreciated in the professional literature.

Considerable improvements in visual acuity were found in half of the Harrell et al. study group. Four subjects, who had previously worn glasses, no longer required them. Our study noted no such improvement. The Harrell group also mentioned one subject whose cataracts, which had been discovered at the onset of the study, stabilized rather than worsened as is typical. Our study's subject population did not include, or intentionally exclude, anyone with cataracts.

The Harrell et al. study made special mention of the improvement in the somatic appearance of children with Down's syndrome, as evidenced by direct clinical examinations and before-and-after photographs. Our research did not note any somatic changes upon physical examination or in before-and-after photographs. Harrell et al. mentioned that some of their subjects showed an improved texture of nails as well as healthier hair and skin. No such changes were reported or clinically observed in our study sample. The Harrell group also stated that several children had improved their level of verbalization and were able to advance considerably in school. Our study noted no such dramatic educational improvements.

There was a greater uniformity of testers in our study than in that of Harrell et al., wherein all subjects were tested by one psychologist and sporadically by six others. In our study, psychometric testing was accomplished by two doctoral level psychologists, who examined each of the subjects serially, and one supervising psychologist, who thoroughly reviewed the findings of the other two testers.

The dietary restrictions used by the Harrell group were also employed and closely monitored in our study. Yet unlike the original GTC supplement used in the Harrell et al. study, which is no longer available, the GTC\#3 utilized in our replication study contained biotin $(300 \mathrm{mg})$ and lacked calcium phosphate $(37.5 \mathrm{mg})$. Although it is possible that these two differences may have had an influence on the divergent results, this seems unlikely.

Harrell and her colleagues stated that six subjects had ceased being hyperactive while involved in their study, and we noted that five of our subjects demonstrated major improvement in general personality calming as well. Initial and final psychiatric interviews confirmed that each of these five youngsters had indeed 
shown moderate behavioral improvement over the eight-month study period. Parental observations and professional examinations, however, did not correlate with whether or not these youngsters were on active or placebo agents. Indeed, the best behavioral improvement was noted in an 11-year-old girl who had been in Group V (placebo/placebo).

Finally, the Harrell et al. study continued the initial placebo group beyond the eight-month period (i.e., placebo for four months and active GTC and thyroid for an additional eight months) and noted significant improvements in this "sub-sample." Ten subjects out of their total sample of 16 had eight months of active agents, whereas six of our subjects had eight months of active agents, and another ten had four months of partially active agents. Six of the subjects' parents in our study requested that their child be allowed to remain on the active vitamin/mineral and thyroid supplements. These children are currently being assessed as to any delayed findings, which will be reported in a future publication.

Our study found no significant ameliorating effects for mentally retarded children given vitamin-mineral and thyroid supplmentation, nor any interaction between the two supplements based on intellectual, social adaptive, and neuropsychological testing measures. While our attempt to replicate the Harrell et al. (2) research design did not confirm the promising results of that specific investigation, nutritional therapies cannot be dismissed out of hand. There are, for example, fourteen known metabolic diseases responsive to megavitamin regimes (18). Frager et al. (19) determined that the administration of $25 \mathrm{mg} / \mathrm{kg}$ of vitamin B6 to infants with Down's syndrome during the first six months of life, and $35 \mathrm{mg} / \mathrm{kg}$ during the following 2.5 years, resulted in increased normalization of cortical auditory evoked potentials. While it is difficult to draw specific clinical conclusions concerning this basic research, it does suggest that some benefit can indeed be incurred through the use of megavitamin therapy.

The tendency in individuals with Down's syndrome toward nutritional deficiencies in vitamin A, vitamin E, ascorbic acid, calcium, copper, magnesium, manganese, nicotinic acid and thiamine, possibly due to impaired absorption, suggests an additional rationale for continuing research (20-23). Kershner and Hawke (24) sought to discriminate between the effects of specific dietary improvement with and without megavitamin therapy, but found no significant differences, although both groups showed a broad range of general improvement. Their findings suggested that diet modification alone was as effective as diet modification plus vitamin supplementation. A recent review of the possible effects of diet on behavior by Wurtman(25) underscores this dimension. Perhaps one of the keys to the discrepancies found in megavitamin study results lies there. None of the previous replications of the Harrell et al. research had emphasized diet modification, and rigorous dietary monitoring demands extremely explicit guidelines. It must also be stressed that the positive results which have come from these types of studies could have been produced by parents who noted improvements, perhaps secondary to real developmental gains, which were due to their own greater efforts and 
involvement with their children. Accordingly, essentially negative findings should be viewed within the complexity of such biopsychosocial challenges.

Perhaps current therapeutic interventions are less specific than will prove necessary. There appears, for example, to be precious little rationale for the use of fat-soluble vitamins in these studies, while the inclusion of certain minerals, such as selenium, seems increasingly indicated. Future research may indeed reveal specific advantages of vitamin-mineral supplementation as a promising treatment intervention in the etiologies which produce the syndromes of mental retardation. Although this goal remains rather elusive at this time, the utilization of such treatment approaches very early in life, below the age of three years, appears to be warranted because of potential developmental enhancement.

This study was supported by grants from the Association for Retarded Citizens of the United States (Arlington, Texas) and the Foundation for Nutritional Advancement (New York, New York).

\section{REFERENCES}

1) Barnes, B., and Galton, L. (1976): Hypothyroidism: Unsuspected Illness, Crowell, New York.

2) Harrell, R., Capp, R., Davis, D., Peerless, J., and Ravitz, L. (1981): Can nutritional supplements help mentally retarded children? An exploratory study. Proc. Natl. Acad. Sci. USA, 78 574-578.

3) Bennett, F., McClelland, S., Kriegsmann, E., BrazeeAndrus, L., and Sells, C. (1983): Vitamin and mineral supplementation in Down's syndrome. Pediatrics, 72, 707-713.

4) Ellis, N., and Tomporowski, P. (1983): Vitamin/mineral supplements and intelligence of institutionalized mentally retarded adults. Am. J. Ment. Defic., 88, 211-214.

5) Smith, G., Spiker, D., Peterson, C., Cicchetti, D., and Justine, P. (1984): Use of megadoses of vitamins with minerals in Down syndrome. J. Pediatr., 105, 228-234.

6) Weathers, C. (1983): Effects of nutritional supplementation on IQ and certain other variables associated with Down syndrome. Am. J. Ment. Defic., 88, 214-217.

7) Turkel, H., Nusbaum, I., and Baker, S. (1984): Intellectual improvement of a retarded patient treated with the "U" Series. J. Orthomol. Psychiatr., 13, 272-281.

8) Ushakov, A., Myasnikov, V., Shestkov, B., Agureev, A., Belakovsky, M., and Rumyantseva, M. (1978): Effect of vitamin and amino acid supplements on human performance during heavy mental and physical work. Aviat. Space Environ. Med., 1184-1190.

9) Pueschel, S., Scofa, F., Perry, C., and Pezullo, J. (1981): Atlanta-axial instability in children with Down's syndrome. Pediatr. Radiol., 10, 129-132.

10) Hathcock, J. (1985): Toxicity of vitamins for vitamin nutrition information service (VNIS). Vitamin Issues, 1, 1-6.

11) Wechsler, D. (1981): Manual for the Wechsler Intelligence Scale-Revised, Psychological Corporation, New York.

12) Doll, E. A. (1965): Vineland Social Maturity Scale, American Guidance Service, Min.

13) Golden, C. J. (1985): Nebraska Neuropsychological Exam: Manual, Western Psychology Services, Los Angeles, Calif.

14) Hie, N. (1983): Statistical Package for the Social Sciences, McGraw-Hill, New York.

Vol. 35, No. 3, 1989 
15) Brin, M. (1964): Erythrocyte as a biopsy tissue for functional evaluation of thiamine adequacy. J. Am. Med. Assoc., 187, 762-766.

16) Menolascino, F., and Egger, M. (1978): Medical Dimensions of Mental Retardation, University of Nebraska Press, Lincoln, Neb.

17) Pueschel, S., and Rynders, J. (1984): Down Syndrome: Advances in Biomedicine and Behavioral Sciences, Ware Press, New York.

18) Hillman, R. E. (1976): Megavitamin responsive aminoacidopathies. Pediatr. Clin. North Am., 23, 557-567.

19) Frager, J., Barnet, A., Weiss, I., and Coleman, M. (1985): A double-blind study of vitamin B6 in Down's syndrome infants, part 2: Cortical auditory evoked potentials. J. Ment. Defic. Res., 29, 241-246.

20) Auld, R., Pommer, A., Houch, J., and Burke. F. (1959): Vitamin A absorption in mongoloid children. Am. J. Ment. Defic., 63, 1010-1017.

21) Matin, M., Sylvester, P., Edwards, D., and Dickerson, J. (1981): Vitamin and zinc status in Down's syndrome. J. Ment. Defic. Res., 25, 121-129.

22) Sylvester, P. E. (1984): Nutritional aspects of Down's syndrome with special reference to the nervous system. Br. J. Psychiatr., 145, 115-121 .

23) Williams, C., Quinn, H., Wright, E., Sylvester, P., Gosling, P., and Dickerson, J. (1985): Xylose absorption in Down's Syndrome. J. Ment. Defic. Res., 29, 173-180.

24) Kershner, J., and Hawke, W. (1979): Megavitamins and learning disorders: A controlled double-blind experiment. J. Nutr., 109, 819-826.

25) Wurtman, R. J. (1987): Nutrients affecting brain composition and behavior. Integrative Psychiatr., 5, 226-257. 